\title{
Optimal water resource allocation modelling in the Lowveld of Zimbabwe
}

\author{
Delight Mhiribidi $^{1}$, Joel Nobert ${ }^{1}$, Webster Gumindoga ${ }^{2}$, and Donald T. Rwasoka ${ }^{3}$ \\ ${ }^{1}$ Department of Water Resources Engineering, College of Engineering and Technology, \\ University of Dar es Salaam, Dar es Salaam, Tanzania \\ ${ }^{2}$ Department of Civil Engineering, University of Zimbabwe, P.O. Box MP167, \\ Mt Pleasant, Harare, Zimbabwe \\ ${ }^{3}$ Upper Manyame Subcatchment Council, Box 1892, Harare, Zimbabwe \\ Correspondence: Delight Mhiribidi (delightmhiribidi@gmail.com)
}

Received: 6 November 2017 - Accepted: 4 December 2017 - Published: 29 May 2018

\begin{abstract}
The management and allocation of water from multi-reservoir systems is complex and thus requires dynamic modelling systems to achieve optimality. A multi-reservoir system in the Southern Lowveld of Zimbabwe is used for irrigation of sugarcane estates that produce sugar for both local and export consumption. The system is burdened with water allocation problems, made worse by decommissioning of dams. Thus the aim of this research was to develop an operating policy model for the Lowveld multi-reservoir system.

The Mann Kendall Trend and Wilcoxon Signed-Rank tests were used to assess the variability of historic monthly rainfall and dam inflows for the period 1899-2015. The WEAP model was set up to evaluate the water allocation system of the catchment and come-up with a reference scenario for the 2015/2016 hydrologic year. Stochastic Dynamic Programming approach was used for optimisation of the multi-reservoirs releases.

Results showed no significant trend in the rainfall but a significantly decreasing trend in inflows $(p<0.05)$. The water allocation model (WEAP) showed significant deficits $(\sim 40 \%)$ in irrigation water allocation in the reference scenario. The optimal rule curves for all the twelve months for each reservoir were obtained and considered to be a proper guideline for solving multi- reservoir management problems within the catchment. The rule curves are effective tools in guiding decision makers in the release of water without emptying the reservoirs but at the same time satisfying the demands based on the inflow, initial storage and end of month storage.
\end{abstract}

\section{Introduction}

Effective water resources management requires optimal water resources allocation systems that maximizes set objectives such as crop yield (Reddy and Kumar, 2007); hydroelectric power generation (Mujumdar and Nirmala, 2007) and other uses such as flood control (Sharma et al., 2016). Optimal water allocation is the consideration of all the water users and allocation of water equitably.

Man-made reservoirs are among the most efficient infrastructures to manage water supply as well as minimise the enormous impacts of droughts. These infrastructures, coupled with the need for improved operational skills of watershed-scale reservoirs and water distribution networks necessitates the development and application of water allocation models (Namchaiswadwong, 2004; Sert et al., 2007; Juízo and Lidén, 2010). Simulation-based allocation models are used to meet this need and they simulate water allocation with pre-determined water use priorities and reservoir operation rules. These models have poor flexibility if anthropogenic and hydro-climatic factors are taken into consideration as they operate in a "what-if-then" scenario (Jha and Gupta, 2003). Therefore considering these limitations, integrated optimal water resources allocation modelling should consider all the water users and equitably allocate water amongst users, whilst taking into consideration hydro-climatic variability. (Tsoukalas and Makropoulos 
1972; Evers, 1992; Arranz and McCartney, 2007; Tilmant et al., 2010; Sharma et al., 2016). A variety of methodologies have been proposed and developed in order to embody in optimal water allocation the uncertainties of various influencing factors and hydro-system characteristics, such as available water flows, water demands, variations in water supplies, corresponding cost and benefit coefficients and policy regulations.

Most water resources systems decisions have to be made in the face of hydrologic uncertainty (Ajami et al., 2008). Rainfall, reservoir inflows, crop evapotranspiration are hydrologic variables which influence water resources decision making and all these variables are stochastic. Therefore application of optimization models for water management have to be formulated in a manner that considers the inherent hydrologic uncertainty in arriving at optimal water allocation decisions.

Stochastic Dynamic Programming (SDP) is a framework for modelling optimisation problems whose variables exhibit some uncertainty. It has been widely used by different researchers and professionals in optimization of reservoir operating policies with uncertainty in inflows.

Sharma et al. (2016) used the SDP approach to optimize the Ukai Reservoir in India. This SDP model which was based on the minimization of least squares sum of actual releases and storages from the respective targets was formulated by Buras (1985).

In the South-Eastern Lowveld of Zimbabwe, water is provided from five reservoirs namely Mutirikwi, Muzhwi, Bangala, Manjirenji and Siya on different river systems for sugarcane production. At present, all sugarcane for milling is grown under irrigation in the South-Eastern part of Zimbabwe. The current water allocation policy of using water permits has resulted in rising conflicts between the water authority and the users as it is a priority based policy. Also, due to the prolonged drought in the country, the reservoirs have been having very low volumes of water which has not been sufficient for irrigation of the crop throughout the past three years. In 2016, three reservoirs, Muzhwi, Bangala and Mutirikwi were temporarily decommissioned (reservoir has a minimum supply of domestic water for twenty one months) due to very low volumes and this put a lot of pressure on the remaining two reservoirs, the farmers and Runde Catchment Council (the authority responsible for water resource management in the basin) on how best to allocate the limited water resources. Thus an optimal multi-reservoir operating policy is needed whereby the releases from the five reservoirs meet existing water demands as much as possible, without emptying the reservoirs and without relying on one reservoir.

\section{Study Area}

The Lowveld of Zimbabwe falls under Runde catchment which is located in the South-Eastern part of Zimbabwe.
Zimbabwe is divided into 7 catchment areas presented in Fig. 1, managed by seven Catchment Councils and 47 subCatchment Councils. The catchment is situated $21^{\circ} \mathrm{S}, 21^{\circ} \mathrm{E}$ and is 400 to $500 \mathrm{~m}$ above sea level. It has an area of approximately $41000 \mathrm{~km}^{2}$ which constitutes $22 \%$ in area of Zimbabwe and $40 \%$ of this catchment area is communal lands (Anderson et al., 1993). It lies in the dry parts of the country which cover Natural Regions III, IV and V with an average of $684 \mathrm{~mm}$ of rainfall per annum and temperatures as high as $43^{\circ} \mathrm{C}$ are experienced (Meteorological Services Department (MSD)). The country is divided into five natural regions based on soil quality, rainfall regime, and vegetation amongst other factors. The land resource quality declines from Natural Region (NR) I through to NR V (Moyo, 2000; Vincent and Thomas, 1961). NR I receives average annual rainfall of more than $1000 \mathrm{~mm}$, NR II between 700 and $1050 \mathrm{~mm}$, NR III receives 500-800 mm, NR IV from 450$650 \mathrm{~mm}$ and NR V receives below $450 \mathrm{~mm}$ (Moyo, 2000; Vincent and Thomas, 1961). Approximately $90 \%$ of the precipitation occurs during the period of mid-November to early April (MSD). The winter season is from April to August, and the hottest and driest period is from September to mid-November. The catchment is characterized by frequent droughts and an annual average evaporative demand of about $1500 \mathrm{~mm}$ (MSD). As a result of the combination of low rainfall and high evaporation, crop production is only possible with irrigation (Anderson et al., 1993).

Sugarcane production has been the mainstay of the Lowveld's economy. The sugar industry has produced significant foreign exchange for the national exchequer not to mention employment, ethanol, various industrial products, and the raw cane sugar which is consumed in large amounts in Zimbabwe. The sugar industry represents $1.4 \%$ of national GDP, and a massive $95 \%$ of Masvingo Province's accountedfor GDP (Scoones et al., 2017). Rainfall and runoff has an impact on the socio-economy of the people living in the Runde catchment and Zimbabwe as a whole hence the need to understand the temporal and spatial variability of both rainfall and runoff which determines the reliability of water supply.

\section{Methodology}

Observed hydrological and meteorological data; reservoir characteristics and operation rules; and water use for the catchment was used in the methodology. Figure 2 shows the flowchart of the methodology used in this study.

\subsection{Assessment of precipitation and flow variability}

The Mann-Kendall (MK) trend and the Wilcoxon signed rank tests were used to assess the presence of trends in the rainfall and inflow data from 1899 to 2015 on a monthly time scale. Data from the four rainfall stations indicated in Fig. 1 was used in the analysis. Eleven gauging stations were used 


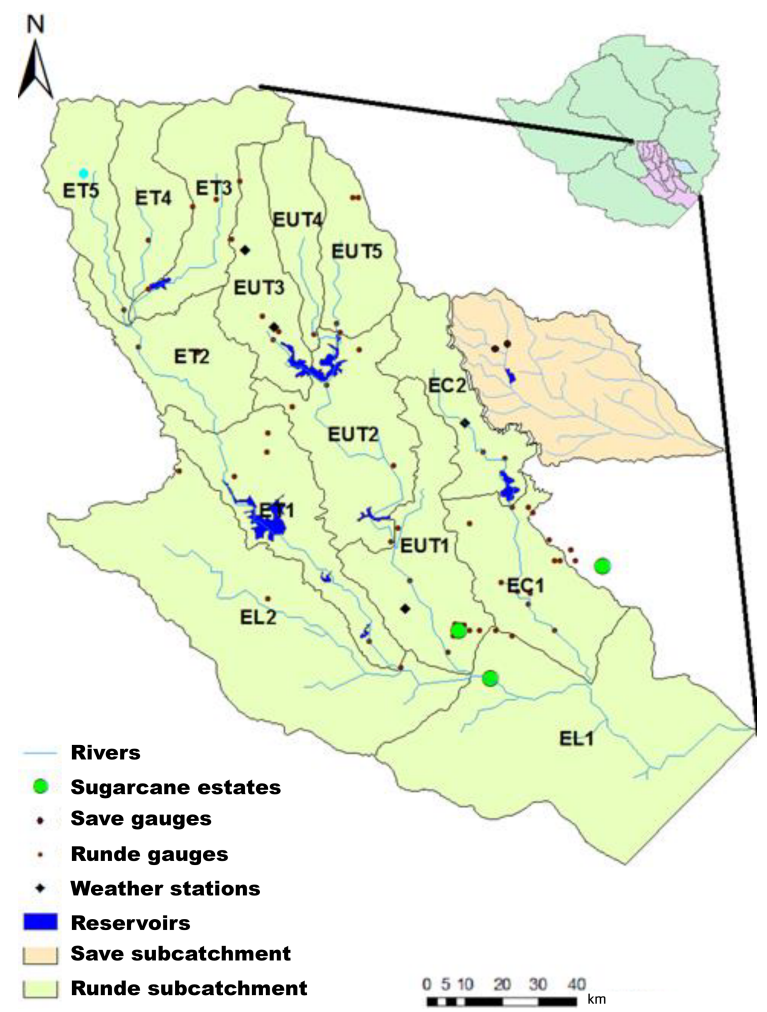

Figure 1. Study area map showing sugarcane estates and the water supplying reservoirs.

as these are the ones which measure the inflow into the five reservoirs. Mann Kendall test was used as there is no need for the data to confirm to any particular distribution and it is less sensitive to sudden breaks due to time series which are inhomogeneous (Jaagus, 2006). To improve the robustness of the results the Wilcoxon Signed rank test was used in detection of significance of difference between two groups of data sets which were divided according to time periods so as compare the medians of two distributions.

\subsection{Assessment of the current water allocation scenario for the catchment}

The Water Evaluation and Planning System (WEAP) model was used to come up with a reference scenario for the 2015/2016 hydrologic year on the water allocation of the catchment and this was used as a baseline for optimization. A default scenario known as the "Reference Scenario" carries forward the Current Accounts data into the entire project period and serves as a point of comparison for other scenarios in which changes may be made to the system data. WEAP was used due to its basic principle of water balance accounting, priority based approach and user friendliness. The Zimbabwe National Water Act (1998) priorities were used in setting up the demand nodes. Water for primary needs is given the first priority, the environment comes second, Mining and

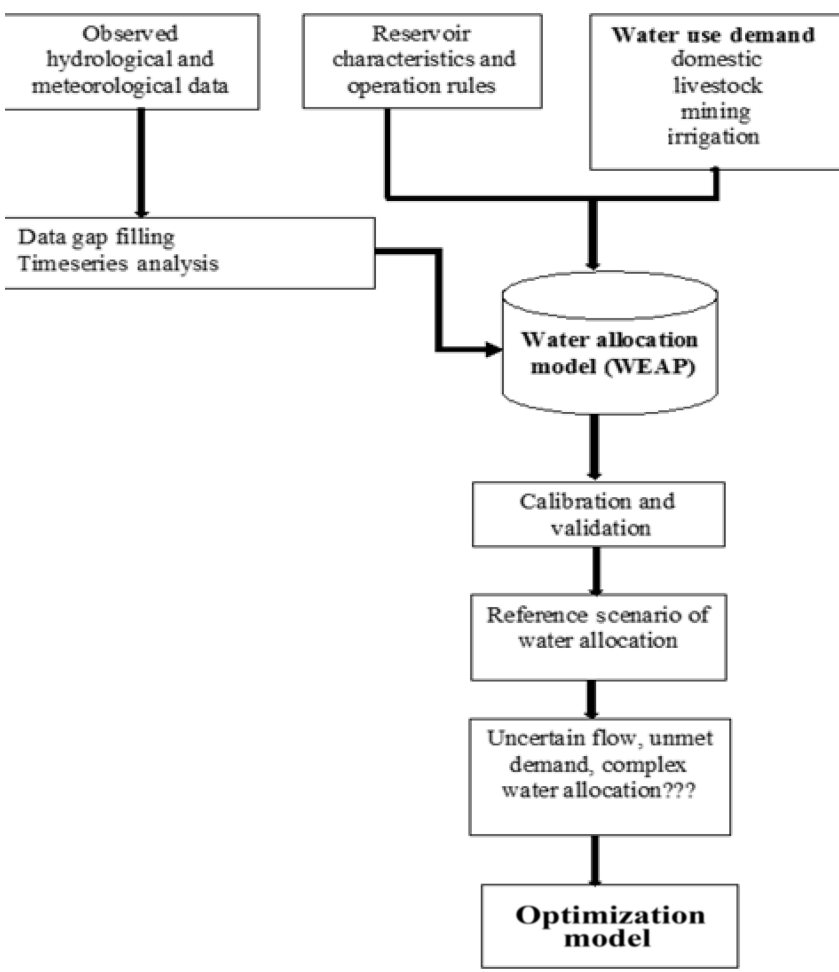

Figure 2. Methodology General Flow Chart.

Industries have a third priority, plantations such as fruit and forestry at the fourth, plantation-crops such as sugar cane are given the fifth priority and lastly seasonal crops have the sixth priority.

\subsection{Optimisation Model (SDP Approach)}

A backward recursive approach was used in coming up with the optimal policy. The SDP model developed was programmed in MATLAB ${ }^{\circledR}$ 2017. Different combinations of reservoir storage states $(k)$ and inflows $(i)$ were considered in coming up with the optimal policy for the reservoirs.

The optimal policies for each reservoir for each month were tabulated for different initial storage classes, inflows and end of month storage. The first-order Markov chain was used in computation of inflow transition probabilities (Vedula and Mujumdar, 2005) for the different months. The transition probabilities were used in the optimisation model represented by Fig. 3 .

\section{Results and Discussion}

\subsection{Variability Analysis for precipitation and flow}

\subsubsection{Trend test results for Rainfall}

Precipitation trend tests showed a decreasing trend although not statistically significant. A negative Sen's slope from Mann Kendall test as well as more negative ranks compared 


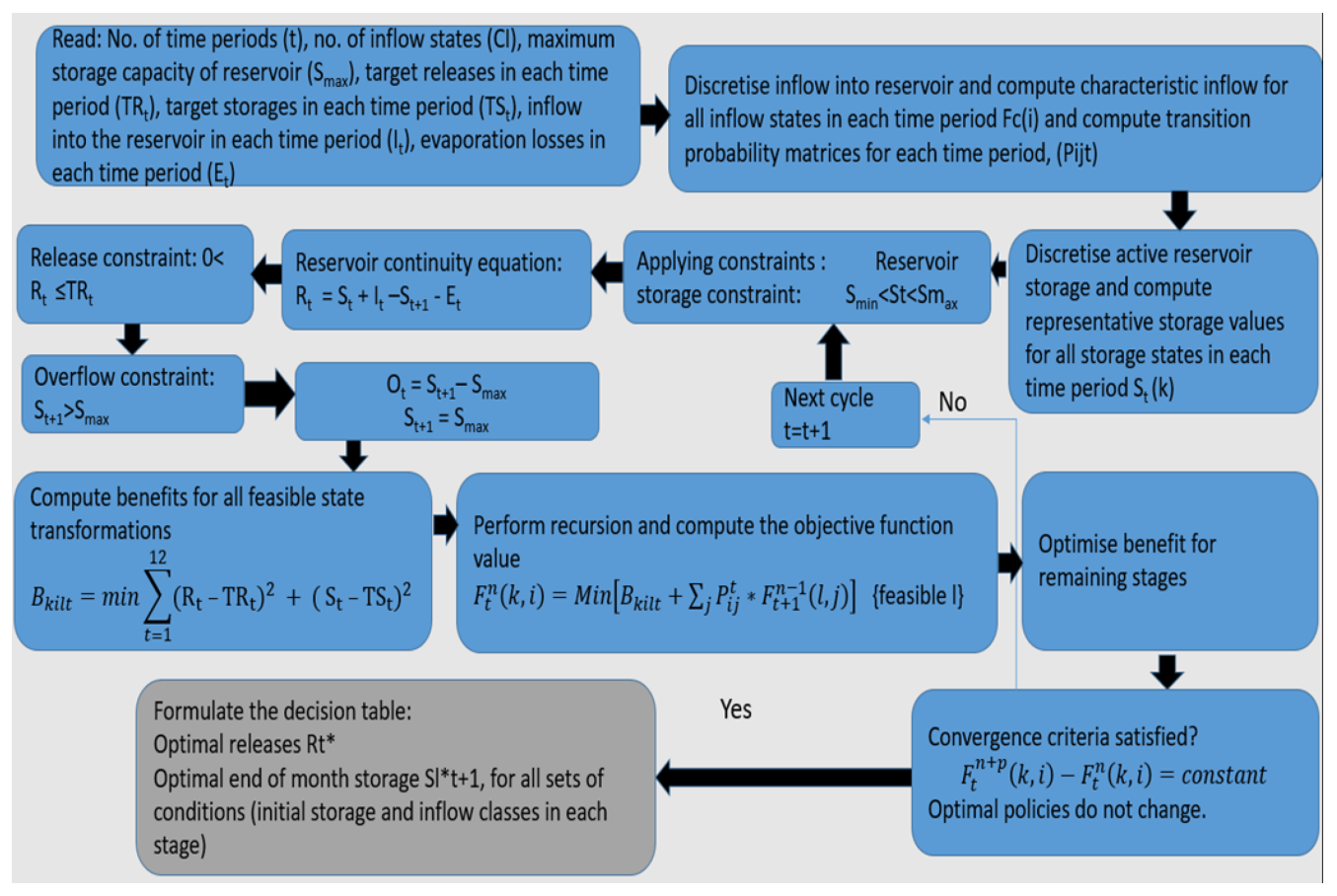

Figure 3. SDP Method Flow chart (Source: Sharma et al., 2016).

to positive ranks from Wilcoxon Signed Rank test were observed. This was predicted to cause a reduction in the runoff and hence the amount of available surface water due to a reduction in the reservoir volumes not only for the Lowveld, but across Zimbabwe.

\subsubsection{Mann Kendall Trend and Wilcoxon Signed Rank Test Results for flows}

There was need to understand the temporal and spatial variability of both rainfall and runoff which determines the reliability of water supply. Both tests showed that there were significant trends in the flows into all the five reservoirs from the eleven gauging stations. An overall decreasing trend was observed in the inflows, thereby a temporal variation experienced in the catchment over the years. The MK results showed nine out of eleven gauging stations having a negative Sen's slope. The Wilcoxon Signed Rank Test results also showed nine of the eleven stations having more negative ranks than positive ranks. Thus there was a significantly decreasing trend in the flows.

\subsection{Assessment of the current water allocation scenario for the catchment}

Table 1 shows the different total annual demand and total unmet annual demand of the subcatchment irrigation demand sites for each individual subzone in the study area map in Fig. 1. A first order validation of the WEAP model was done comparing the simulated flows to the observed flows. The
Table 1. 2015/2016 hydrologic year total demand and unmet demand for Irrigation.

\begin{tabular}{lrr}
\hline $\begin{array}{l}\text { Irrigation } \\
\text { Demand site }\end{array}$ & $\begin{array}{r}\text { Total Demand } \\
\text { (cumecs) }\end{array}$ & $\begin{array}{r}\text { Total Unmet } \\
\text { Demand (cumecs) }\end{array}$ \\
\hline EC1 & 112.80 & 91.93 \\
EC2 & 292.49 & 238.38 \\
EL1 & 282.00 & 157.99 \\
EL2 & 52.92 & 11.64 \\
ET1 & 12.16 & 6.35 \\
ET2 & 40.64 & 21.25 \\
ET3 & 143.21 & 93.90 \\
ET4 & 3.53 & 1.85 \\
ET5 & 0.90 & 0.47 \\
EUT1 & 240 & 134.48 \\
EUT2 & 1550.08 & 1199.64 \\
EUT3 & 2.8 & 2.13 \\
EUT4 & 1.2 & 0.91 \\
EUT5 & 7.42 & 5.65 \\
\hline Total & 2742.13 & 1966.579 \\
\hline
\end{tabular}

Nash-Sutcliffe efficiency (NSE) was used as an indicator of the model performance. The NSE for the different river systems ranged from 0.66-0.99. A large monthly variation in irrigation water demands existed with the dry season of July to November having the highest unmet demand. Unmet demand is the amount of water not satisfied to the user (shortage).

The high unmet demands could be due to the decommissioning of the three major reservoirs which supply irrigation 


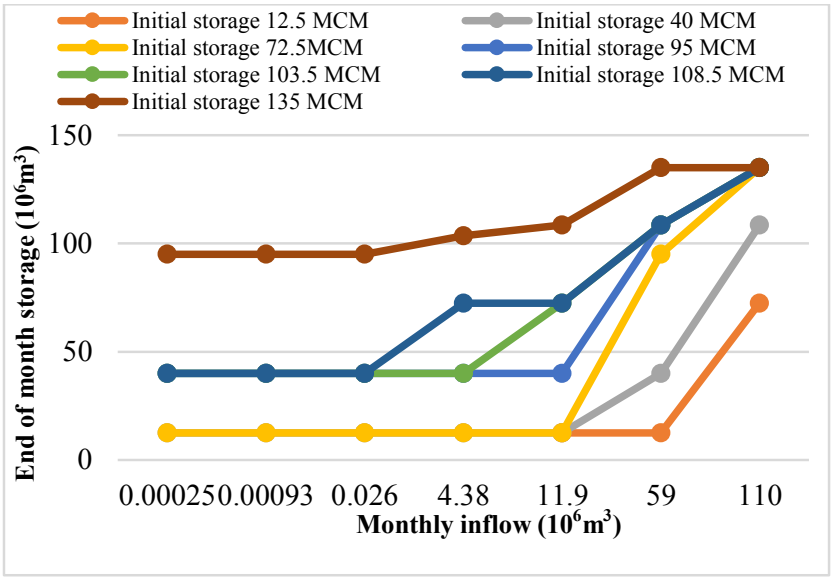

Figure 4. Muzhwi March Rule curve.

water to the estates and also due to the current water allocation priorities of the water authority.

\section{3 (SDP) Optimal Policy}

Figure 4 shows that in March, the target release was 32.94 MCM whilst the target storage was expected to be the full reservoir capacity of $158 \mathrm{MCM}$ because this will be towards the end of the rainy season to ensure maximum efficiency of the project in meeting conservation demands during the lean period.

For Siya reservoir, in February, the target release was $38.92 \mathrm{MCM}$ and storage was $90 \mathrm{MCM}$. The target storage is not met for most of the different combinations. The demands are mostly met by the different combinations of initial storages and the inflows as shown in Fig. 5.

From the five different reservoirs, for all the different combinations of initial storage states and inflows coming into the reservoirs, the model tries its best to get a balance between the target storage and the target release. All the results from the different reservoirs show that at any particular moment, there is a possible amount of water that can be released in trying to meet the target release and at the same time the reservoir would not be emptied. All the minimum storages were above the decommissioning level (twenty-one months' supply of primary water use), thus it can be used as a flexible tool for allocation tool in the semi-arid catchment which has competing and conflicting uses.

Operating one reservoir at a time might not fully satisfy all the desired targets but if water can be released from all the different reservoirs depending on the initial state of storage and the inflow received, the demands can be fully met.

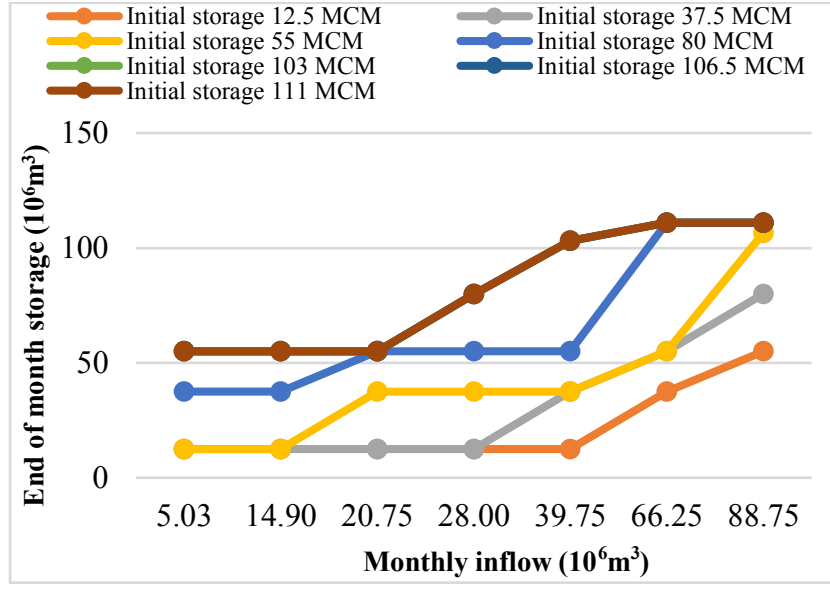

Figure 5. Siya February Rule Curve.

\section{Conclusions}

There was no statistically significant trend in monthly rainfall for the period 1899-2010 but there was a statistically significant decreasing trend for the monthly reservoir inflows from 1959-2015.

The current water allocation method has huge deficits within the catchment which compromises the crop yield and thereby economic benefits not recognised as expected. The irrigation unmet demand (approximately $70 \%$ of the total annual demand) is the largest due to the priority based allocation approach and therefore there is need for a better water allocation approach in the study area which can optimise benefits to the different water users.

The operation policies derived from the SDP model for each month and for each reservoir are more stable and adaptable for release decisions due to fluctuations in the inflows into the reservoir.

A crop yield optimisation approach for the study area may yield better results as it addresses the optimal yield that can be obtained depending on the amount of water released at any particular time. This may consider the critical stages of the crop growth which have to be given priority so as to maximise the crop yield.

The proposed rule curves can serve as a decision-making tools for long-term operation of the reservoirs, thereby maximizing the benefits derived from the reservoir.

Data availability. The data used in the research can be accessed on request from the researchers.

Competing interests. The authors declare that they have no conflict of interest. 
Special issue statement. This article is part of the special issue "Understanding spatio-temporal variability of water resources and the implications for IWRM in semi-arid eastern and southern Africa". It is a result of the IAHS Scientific Assembly 2017, Port Elizabeth, South Africa, 10-14 July 2017.

Acknowledgements. The first author wishes to acknowledge the financial support received from WaterNet Organisation.

Edited by: Hodson Makurira

Reviewed by: Evison Kapangaziwiri and one anonymous referee

\section{References}

Ajami, N. K., Hornberger, G. M., and Sunding, D. L.: Sustainable water resource management under hydrological uncertainty, Water Resour. Res., 44, 1-10, 2008.

Anderson, I. P., Moyo, M., Nyamwanza, B., and Brinn, P. J.: Physical resource inventory of the communal lands of Zimbabwe-An Overview, NRI Bulletin 60, Chatham, UK: Natural Resource Institute, 1993.

Arranz, R. and Mccartney, M.: Application of the Water Evaluation And Planning (WEAP) Model to Assess Future Water Demands and Resources in the Olifants Catchment, South Africa (No. H040224), International Water Management Institute, available at: http://www.iwmi.cgiar.org/Publications/Working Papers/working/WOR116.pdf, (last access: 31 January 2018), 2007.

Buras, N.: An application of mathematical programming in planning surface water storage, J. Am. Water Resour. As., 21, 10131020, 1985.

Evers, A. J. M.: Optimizing intra- and inter-seasonal water allocation from an irrigation reservoir subject to stochastic inflows, A Thesis Submitted for the Degree of Doctor of Philosophy, Oklahoma State University, 1992.

Jaagus, J.: Climatic Changes in Estonia during the Second Half of the 20th Century in Relationship with Changes in LargeScale Atmospheric Circulation, Theor. Appl. Climatol., 83, 7788, 2006.

Jha, M. and Gupta, A. D.: Application of Mike Basin for Water Management Strategies in a Watershed, Water Int., 28, 27-35, 2003.

Juízo, D. and Lidén, R.: Modeling for transboundary water resources planning and allocation: the case of Southern Africa, Hydrol. Earth Syst. Sci., 14, 2343-2354, https://doi.org/10.5194/hess-14-2343-2010, 2010.
Moyo, S. (Ed.): Zimbabwe environmental dilemma: balancing resource inequities, Harare, Zimbabwe Environmental Research Organisation, 161 pp., 2000.

Mujumdar, P. P. and Nirmala, B.: A Bayesian stochastic optimization model for a multi-reservoir hydropower system, Water Resour. Manag., 21, 1465-1485, https://doi.org/10.1007/s11269006-9094-3, 2007.

Namchaiswadwong, K., Bhaktikul, K., and Kongjun, T.: Optimization Of Multiple Reservoir Releases Using Genetic Algorithms: Case Study Of Mae Klong River Basin, Thailand, 5th Thaicid National Symposium, p. 10, Beijing, THAICID, 2004.

Reddy, M. J. and Kumar, D. N.: Optimal reservoir operation for irrigation of multiple crops using elitist-mutated particle swarm optimization, Hydrolog. Sci. J., 52, 686-701, https://doi.org/10.1623/hysj.52.4.686, 2007.

Scoones, I., Mavedzenge, B., and Murimbarimba, F.: Sugar, People and Politics in Zimbabwe's Lowveld, J. S. Afr. Stud., 43, 567584, https://doi.org/10.1080/03057070.2016.1187972, 2017.

Sert, M., Opan, M., and Temiz, T.: Multiobjective Optimal Planning in Multiple Reservoir Systems, International Congress on River Basin Management, 554-567, 2007.

Sharma, P. J., Patel, P. L., and Jothiprakash, V.: Efficient discretization of state variables in stochastic dynamic programming model of Ukai reservoir, India, ISH J. Hydraul. Eng., 22, 293-304, https://doi.org/10.1080/09715010.2016.1204632, 2016.

Tilmant, A., Kinzelbach, W., Beevers, L., and Juizo, D.: Optimal Water Allocation in the Zambezi Basin, 9th International Congress on Environmental Modelling and Software, 188, available at: https://scholarsarchive.byu.edu/iemssconference/2010/ all/188 (last access: 31 January 2018), 2010.

Tsoukalas, I. and Makropoulos, C.: Hydrosystem Optimization With the Use of Evolutionary Algorithms?: the Case of Nestos River, 13th International Conference on Environmental Science and Technology (CEST2013), At Athens, Greece, 1972.

Vedula, S. and Mujumdar, P. P.: Water Resources Systems, New Delhi, India, Tata McGraw-Hill Education, 2005.

Vincent, V. and Thomas, R. G.: An agro-ecological survey of Southern Rhodesia: Part I agro-ecological survey, Salisbury, Government Printers, 1961.

Zimbabwe Water Act: chap. 20:24, Harare, Government Printers, available at: www.parlzim.gov.zw/acts-list/water-act-20-24, (last access: 31 January 2018), 1998. 